\title{
Changing Corporate Practices to Reduce Cancer Disparities
}

\author{
Nicholas Freudenberg, DrPH, MPH \\ Sandro Galea, MD, MPH, DrPH \\ Marianne Fahs, $\mathrm{PhD}, \mathrm{MPH}$
}

\begin{abstract}
While reducing racial/ethnic and socioeconomic disparities in cancer mortality has been identified as a national goal, current policies are unlikely to achieve it. In order to advance the development of policies for the primary prevention of cancer and cancer disparities, we propose that the practices of the tobacco, alcohol, and food industries be considered as modifiable social determinants of health. We review evidence that the practices of these industries in product design, marketing, retail distribution, and pricing contribute to cancer risk behavior, incidence, and disparities, then examine public health strategies designed to reduce health-damaging practices of these industries and encourage healthier alternatives. We conclude with recommendations for research, practice, and policy that could contribute to the development of less carcinogenic corporate practices.
\end{abstract}

Key words: Cancer prevention, health disparities, health policy, primary prevention.

$\mathrm{T}$

he United States has made eliminating racial/ethnic and other disparities in health a national goal ${ }^{1}$ and the National Cancer Institute and the American Cancer Society have committed to reducing disparities in cancer incidence and mortality. ${ }^{2,3}$ To date, however, most cancer research has focused on secondary prevention and treatment. The evidence base for developing policies for the primary prevention of cancer is limited, making it more difficult to achieve significant progress towards the goal of reducing cancer disparities. Research shows that tobacco and alcohol use and diet play central roles in the etiology of many types of cancer, ${ }^{3-5}$ yet modifying behavior one person at a time has proven to be only modestly effective in reducing the incidence of new cancers. Compelling evidence suggests that the behavior of organizations such as governments and corporations also plays a central role in explaining the incidence and distribution of cancer. ${ }^{4,5}$

More specifically, in this commentary we assess whether corporate practices, such as advertising, product design, pricing, retailing, and political lobbying for market

NICHOLAS FREUDENBERG is a Distinguished Professor of Urban Public Health at Hunter College, where he can be reached at 425 East 25th Street, New York, NY 10010; (212) 481-4363; nfreuden@hunter .cuny.edu. SANDRO GALEA is an Associate Professor in the Department of Epidemiology at the University of Michigan at Ann Arbor and MARIANNE FAHS is a Professor of Urban Public Health at Hunter. 
advantage, might contribute to disparities in the incidence of cancer among different racial/ethnic and socioeconomic groups. In particular, we examine whether the practices of the tobacco, alcohol, and food industries might contribute to the incidence and distribution of lung, breast, cervical, liver, colon/rectum, prostate, pancreatic, and other cancers, which account for about half of U.S. cancer incidence and mortality and a significant portion of cancer disparities. ${ }^{2,3}$

In the course of the paper, we consider corporate policies as social determinants of disparities in cancer incidence and mortality between racial/ethnic groups and between populations with higher and lower socioeconomic status. We identify and describe the pathways by which specific corporate practices contribute to disparities in cancer and discuss the societal costs that may be associated with these practices and their influence on population health. We conclude with a discussion of public health strategies that can be used to change corporate practices that increase access to and distribution of carcinogenic products. Our ultimate goal is to suggest research, policy, and practice directions that can reduce cancer incidence and disparities by changing the practices of the tobacco, alcohol, and food industries.

\section{Disparities in Cancer Morbidity and Mortality in the U.S.}

Despite recent progress in reducing the death rate from cancer, the U.S. still reports increasing cancer incidence in several major types of cancer and sharp racial/ethnic and socioeconomic disparities in incidence or mortality from lung, breast, cervical, liver, stomach, colon and other cancers. ${ }^{3,6}$ Several organizations, including the Institute of Medicine, ${ }^{7}$ the National Cancer Institute, the U.S. Department of Health and Human Services (DHHS), ${ }^{1}$ and the American Cancer Society have made reducing or eliminating these disparities a major priority.

As shown in Table 1, the incidence and mortality rates for most major cancers related to tobacco use, alcohol, and diet are consistently higher for African Americans than for Whites. African American males have higher incidence and mortality rates than Whites for six of seven sites shown below, and African American females have higher incidence rates for four and higher mortality rates for seven of eight sites. Together, these types of cancer account for more than half of all estimated new cases and more than $60 \%$ of the estimated deaths in the U.S. in 2005. Latinos, Asian Americans, and Native Americans also have higher incidence and mortality rates from liver cancer than Whites have. ${ }^{3,6}$

Socioeconomic status also contributes to disparities in cancer. In 1991, Dr. Samuel Broder, then Director of the National Cancer Institute (NCI), observed that "poverty is a carcinogen." An NCI study comparing U.S. cancer mortality by county showed that poorer counties had higher mortality rates for colorectal and prostate cancer and that overall cancer mortality for men living in poorer counties was $13 \%$ higher than for men in better-off counties. ${ }^{9,10}$ Risk factors for cancer also vary by race/ethnicity and socioeconomic status. ${ }^{7,11,12}$ Those with incomes less than twice the poverty level are much more likely to be smokers than those with higher incomes; ${ }^{13}$ obesity levels are higher among African Americans and Latinos and lower-income groups than among their respective counterparts. ${ }^{14}$ While the proportion of alcohol users increases with 


\section{Table 1.}

\section{U.S. CANCER INCIDENCE AND MORTALITY, SELECTED SITES}

\begin{tabular}{|c|c|c|c|c|c|c|c|}
\hline \multirow[b]{2}{*}{ Type of cancer } & \multirow{2}{*}{$\begin{array}{c}\text { Total } \\
\text { estimated } \\
\text { new cases } \\
2005\end{array}$} & \multirow{2}{*}{$\begin{array}{c}\text { Estimated } \\
\text { deaths } \\
2005\end{array}$} & \multicolumn{2}{|c|}{$\begin{array}{c}\text { Black/white } \\
\text { incidence } \\
\text { ratios }\end{array}$} & \multicolumn{2}{|c|}{$\begin{array}{c}\text { Black/white } \\
\text { mortality } \\
\text { ratios }\end{array}$} & \multirow{2}{*}{$\begin{array}{c}\text { Evidence of } \\
\text { causal factors } \\
\text { related to } \\
\text { tobacco }(\mathrm{T}) \text {, } \\
\text { alcohol }(\mathrm{A}), \\
\text { or food }(\mathrm{F})\end{array}$} \\
\hline & & & Male & male & Male & male & \\
\hline Prostate & 232,090 & 30,350 & 1.6 & - & 2.4 & - & $\mathrm{F}(?)$ \\
\hline $\begin{array}{l}\text { Lung and } \\
\text { bronchus }\end{array}$ & 172,570 & 163,510 & 1.5 & 1.0 & 1.4 & 1.0 & $\mathrm{~T}$ \\
\hline $\begin{array}{l}\text { Colon and } \\
\text { rectum }\end{array}$ & 145,290 & 56,290 & 1.1 & 1.2 & 1.4 & 1.4 & T,A,F \\
\hline Urinary system & 101,880 & 26,590 & .5 & .8 & .7 & 1.3 & $\mathrm{~T}$ \\
\hline Pancreas & 32,180 & 31,800 & 1.4 & 1.5 & 1.3 & 1.4 & $\mathrm{~T}, \mathrm{~F}$ \\
\hline $\begin{array}{l}\text { Oral cavity } \\
\text { and pharynx } \\
\text { Liver } \\
\text { Esophagus }\end{array}$ & $\begin{array}{l}29,730 \\
17,550 \\
14,520\end{array}$ & $\begin{array}{r}7,320 \\
15,420 \\
13,570\end{array}$ & $\begin{array}{l}1.3 \\
1.7 \\
1.4\end{array}$ & $\begin{array}{l}0.9 \\
1.5 \\
2.0\end{array}$ & $\begin{array}{l}1.9 \\
1.5 \\
1.6\end{array}$ & $\begin{array}{l}1.3 \\
1.4 \\
1.9\end{array}$ & $\begin{array}{l}\text { T,A } \\
\text { A } \\
\text { T,A, F }\end{array}$ \\
\hline Total & 745,810 & 344,850 & & & & & \\
\hline $\begin{array}{l}\text { Sources: Colditz } \\
\text { Harvard report on } \\
\text { approaches. Canc } \\
\text { facts \& figures for } \\
\text { Advances in canc } \\
\text { menting intervent }\end{array}$ & $\begin{array}{l}\text { Samplin-S } \\
\text { ancer preven } \\
\text { Causes Con } \\
\text { frican Amer } \\
\text { epidemiolog } \\
\text { as. Annu Re }\end{array}$ & $\begin{array}{l}\text { algado M, Ry } \\
\text { tion, volume } \\
\text { trol. 2002;13( } \\
\text { icans. Atlant } \\
\text { y: understan } \\
\text { v Public Heal }\end{array}$ & $\begin{array}{l}\text { CT, et } \\
\text { ulfillin } \\
\text { 199-21 } \\
\text { A: AC } \\
\text { g causa }\end{array}$ & $\begin{array}{l}\text { al. Har } \\
\text { g the po } \\
\text { 2; Amer } \\
\text { S, 2005; } \\
\text { al mech }\end{array}$ & $\begin{array}{l}\text { vard Cent } \\
\text { otential for } \\
\text { rican Can } \\
\text {; Schotten } \\
\text { anisms an }\end{array}$ & $\begin{array}{l}\text { ter for } \\
\text { r cance } \\
\text { cer So } \\
\text { feld D } \\
\text { ad the }\end{array}$ & $\begin{array}{l}\text { ncer Prevention } \\
\text { revention: policy } \\
\text { y. (ACS) Cance } \\
\text { ebe-Dimmer JL } \\
\text { dence for imple }\end{array}$ \\
\hline
\end{tabular}

income, poor, Black and Hispanic problem drinkers are less likely to get help for these problems. $^{15,16}$

Many of the differences in cancer incidence have been attributed to differences in health behaviors such as tobacco, alcohol use, and diet. However, public health interventions designed to change individual behavior or modify environments at the community level have proven to be only modestly successful and have not served to reduce cancer disparities. By accelerating changes in behavior, it may be possible to achieve greater reduction in cancer, ${ }^{17}$ policy change may be a more effective acceleration tool than individual-level interventions. In fact, Link and Phelan ${ }^{18}$ and others have argued that strategies that rely only on providing individuals with health information can exacerbate rather than reduce disparities by providing greater benefits to those with more education and resources. The growing concentration of tobacco-related illnesses among low-income and African American and Latino U.S. populations illustrates this phenomenon. ${ }^{13,19}$ 
In the last decade, epidemiological, public policy, and economic research has demonstrated that practices of industries such as the tobacco, alcohol, and food may contribute to behaviors and environments that increase cancer risk..$^{20,21,22,23}$ During this same period, public health professionals, health and consumer advocates, and elected officials have worked to modify corporate practices that harm health. ${ }^{20,21,22,23,24}$ However, to date there has been little discussion about how corporate practices may influence cancer disparities, and there is a paucity of work that has presented public officials and public health departments with well-articulated policy options for primary prevention of cancer that move beyond individual behavior change. This commentary is an attempt to address this gap.

\section{Addressing Social Determinants of Health in Order to Reduce Disparities}

In recent years, health researchers and social epidemiologists have devoted new attention to the social determinants of health, studying how factors such as income, social status, education, employment, occupation, social and physical environments, culture, and stigma influence health, and developing various conceptual models to explain these relationships. ${ }^{25,26,27}$ Arguing that individual behavior and genetic influences account for only a portion of the burden of ill health, and that medical interventions and individually-targeted health education can have only a modest impact on population health, these investigators make the case for modifying social determinants as a strategy for primary prevention. ${ }^{28,29}$ Link and Phelan ${ }^{18}$ distinguish between fundamental (or underlying) and proximate causes of ill health and argue that health interventions that fail to address underlying causes of illness merely redistribute the burden of disease, often to more vulnerable populations. Modifying fundamental causes has the potential to reduce incidence of diseases such as cancer and, by targeting such interventions to the most vulnerable, to reduce disparities in health. ${ }^{30}$

Research on disparities in cancer has identified various social determinants including poverty, less formal education, racism, and limited access to health care. ${ }^{7,31,32}$ Of these, disparities in access to and quality of health care have been best studied, showing that differences in screening practices, early intervention, and treatment contribute to disparities in cancer mortality. ${ }^{7,12,33}$ While this research suggests important priorities for health care policy, it does not address primary prevention of cancer. A few researchers have noted that differential targeting of lower socioeconomic status (SES) and ethnic/racial groups by the tobacco, alcohol, and food industries may contribute to disparities in cancer, ${ }^{20,34,35,36}$ but little systematic research has taken the practices of these industries to be a fundamental social determinant of health that could be modified to contribute to primary prevention of cancer. In the following section we summarize the available literature about practices of tobacco, alcohol, and food industries as determinants of cancer risk in an effort to identify both what we know about the influence of corporate practices, and gaps in our knowledge that may guide future research. 


\section{Practices of Tobacco, Alcohol, and Food Industries as Determinants of Cancer Risk}

Tobacco. Tobacco use is the largest preventable cause of premature death and disease in the United States, accounting for an estimated 478,000 deaths per year. ${ }^{37}$ About 30\% of U.S. cancer deaths are attributable to active smoking, and tobacco use contributes to 16 types of cancer, including lung, colon and rectum, stomach, liver, and others. ${ }^{37}$ Cigarette smoking causes more than $85 \%$ of lung cancer deaths. ${ }^{37}$ Broadly speaking, without a tobacco industry that aggressively promotes and distributes affordable tobacco products, illnesses and deaths from tobacco use would decline precipitously. More narrowly, industry practices that have been linked to morbidity and mortality include advertising targeted at young people; ${ }^{38,39}$ product promotions and corporate sponsorships; ${ }^{40}$ political opposition to clean air laws, tobacco excise taxes and publicly supported counter-advertising and other legislation, ${ }^{41}$ misrepresentation or withholding of scientific evidence on the health consequences of tobacco use; ${ }^{23}$ and media campaigns emphasizing individual responsibility for tobacco use. ${ }^{42}$

Alcohol. While hepatocellular cancer (HCC) is relatively rare, it is the most rapidly increasing type of cancer in the U.S., in part because of the spread of Hepatitis C virus, a predisposing factor. ${ }^{43}$ Alcohol abuse leads to 32 to $45 \%$ of HCC cases in the United States. ${ }^{44}$ In addition, recent research suggests that increasing incidence of diabetes mellitus and fatty liver disease may also contribute to HCC incidence, ${ }^{45}$ suggesting a possible role for diet as well. Tobacco and alcohol in excess of three drinks per day interact to increase the risk of liver, breast, and colorectal cancers. ${ }^{35}$ It is estimated that combined exposure to alcohol and tobacco account for at least $75 \%$ of U.S. cancers of the oral cavity, pharynx, larynx, and esophagus. ${ }^{36}$

Alcohol industry practices associated with excess alcohol consumption include targeting advertising towards young people ${ }^{46}$ and heavy drinkers, two groups that account for half the alcohol consumed in the U.S.; designing and marketing alcohol products to appeal to new markets, including young people; sponsoring sports events in order to create the norm that sports and alcohol go together; ${ }^{47}$ making alcohol more available in low-income and Black and Latino communities, ${ }^{47}$ and working in the political arena to oppose excise taxes, counter-advertising, and other alcohol control measures. ${ }^{22}$ These activities are designed to maintain alcohol sales and may therefore contribute to incidence of alcohol-related diseases.

Food. In research from the 1980s and 1990s, McGinnis and Foege ${ }^{48}$ estimated that $14 \%$ of all deaths were attributable to diet and physical inactivity while, earlier, Doll and Peto ${ }^{49}$ estimated that $35 \%$ of cancer deaths were attributable to diet alone. More recently, researchers have debated the extent to which diet influences either the incidence or progression of cancer. ${ }^{50,51}$

An emerging consensus is that the previous approach that focused on the role of individual foods or nutrients (e.g., fiber, fat, Vitamin E), as either risk or protective factors, may oversimplify the complex role of diet in carcinogenesis. A more useful approach might be to look at overall composition and balance of diet and the quantity of overall food intake rather than single components. The emerging evidence that 
obesity is a risk factor for cancer ${ }^{51,52}$ is cause for alarm, given the rapid rise in global obesity rates.

Several recent studies show a clear relationship between diet and cancer mortality. For example, Mai et al. ${ }^{53}$ found that an overall diet in a national sample of U.S. women, measured by the Recommended Food Score as having a sum of 23 recommended food items, was inversely associated with overall mortality from cancer, and especially breast, colon/rectum, and lung cancers, as well as with incidence of lung cancer. Fairly consistent evidence suggests that diets high in fruits and vegetables may protect against cancer. ${ }^{17,54}$ The American Cancer Society cohort study estimated that the preventive impact of maintaining a body mass index (BMI) of less than 25 was a $15-25 \%$ reduction of cancer deaths in women and $10-14 \%$ in men, a total of 90,000 cancer deaths per year. ${ }^{55}$

Unlike tobacco or alcohol, food is a necessary product for human health, and food producers have the potential to promote health. However, the food industry has consistently used product design, advertising, pricing, sponsorship of scientific research, lobbying, campaign contributions, and other strategies to influence individual dietary behavior in ways that support profitability but not human health. ${ }^{20}$ Partly as a result, the American diet better reflects the food choices promulgated by the food industry than the food choices recommended by nutritionists. ${ }^{56}$ As Nestle ${ }^{57}$ has observed, the single most important nutritional health message for the American people is to eat less, yet the food industry has successfully opposed this message and dominates public discourse on food with the message to eat more. For example, by supporting professional nutrition organizations to endorse its views, by promoting voluntary rather than mandatory guidelines on school food sales and advertising to children, and by emphasizing physical inactivity rather than nutrition as the cause of obesity, the food industry has made it more difficult to reduce obesity rates. ${ }^{20,57}$ Recent research linking obesity and overall food consumption to various forms of cancer ${ }^{52}$ suggests that modifying industry practices that encourage obesity (in concert with increasing opportunities for physical activity) may be a promising strategy for primary prevention of several types of cancer.

In sum, it is estimated on the basis of epidemiologic studies, that in industrialized countries effective interventions to eliminate tobacco smoking and environmental tobacco smoke, to moderate alcohol consumption, and to reverse the rising prevalence of obesity would result in a $50 \%$ reduction in cancer mortality. ${ }^{44}$ No other medical advances promise such potential.

\section{Industry Practices as Determinant of Disparities}

The above review suggests that the tobacco, alcohol, and food (TAF) industries use similar strategies to promote their products, to encourage higher levels of consumption, and to resist public efforts to reduce use. Previous work ${ }^{21}$ and a variety of evidence from industry-specific studies suggest that several TAF industry practices warrant further investigation for their role in increasing cancer risk. These include advertising, ${ }^{47,58,59}$ product availability through retail density, ${ }^{60,61}$ pricing, ${ }^{62,63}$ and political opposition to public health prevention policies that threaten profitability. ${ }^{20,64,65}$ Credible (if contested) 
evidence demonstrates that each of these practices contributes to increased consumption of a cancer-causing product and the observed variability of these industry practices by population or community, suggesting a possible role in health disparities. Moreover, successful public health campaigns to modify these practices suggest the plausibility of policy interventions. ${ }^{20,21,66,67}$

A few examples illustrate the breadth of this research. Research has demonstrated that

- Tobacco, alcohol, and food companies target advertising at Blacks and at lower-income communities, leading to greater exposure to health-damaging messages. $^{35,47,68}$

- Decisions about where to locate retail outlets and the density of such outlets result in differential access by socioeconomic status and race/ethnicity to unhealthy products such as tobacco, alcohol, and high fat foods and less access to healthy products such as fresh fruits and vegetables. ${ }^{61,62}$ For example, a study in Detroit found that the nearest supermarket was, on average, 1.1 miles further away from neighborhoods in which African Americans resided than from White neighborhoods. ${ }^{69}$

- Product promotions and corporate sponsorships often target vulnerable groups. ${ }^{40,63}$

- Existing government regulation (such as restrictions on the sale of single cigarettes, bans on indoor smoking, placement of tobacco and billboard advertising, or food safety rules) may be enforced differently in African American and lowincome neighborhoods compared with White and better-off neighborhoods. ${ }^{34,70}$ For example, one California study found that underage Black and Latino youth were 2.5 times more likely to be sold cigarettes than their White counterparts. ${ }^{34}$

- Vulnerable populations may have less access to public health campaigns that provide the knowledge and skills to reduce the impact of health-damaging industry practices. ${ }^{68}$

These practices contribute to differences by race/ethnicity and class in use of cancercausing products. ${ }^{46,71,72}$ Although a wide body of literature has demonstrated these differential exposures to tobacco, alcohol, and food industry practices and linked them to higher levels of cancer risk behavior, to date little research has compared the relative contribution of different practices across industries, attempted to assess the cumulative burden of these practices, or systematically examined the benefits of public policies designed to prevent cancer and other diseases by modifying tobacco, alcohol, and food industry practices.

A clear understanding of the mechanisms or pathways by which specific corporate practices contribute to cancer disparities and the relative magnitude of the cancer burden associated with different practices and industries could help to identify policy priorities for primary prevention. When combined with systematic analyses of the efficacy of strategies to change corporate practices, such information could provide health officials with evidence-based guidance for cancer prevention policies. 


\section{Strategies to Change Corporate Practices}

In recent years, several organizations have mobilized to change the practices of the tobacco, food, and alcohol industries. For example, national advocacy organizations such as the Center for Science in the Public Interest and the Union of Concerned Scientists; professional organizations such as the American Cancer Society and the American Diabetes, Heart, and Lung Associations; state and local elected officials and health departments; and grassroots coalitions have all worked to force the withdrawal of unhealthy new products, to require companies to fund public health campaigns, to discourage use of unhealthy products by raising taxes or restricting access, and to restrict corporate influence in the political process. ${ }^{73,74,75}$ These campaigns have operated at the national, state, and local levels and used legislative, electoral, legal, media, and community organizing strategies. ${ }^{74}$ While many scientists, journalists, and advocates have written about a single campaign or a single industry, only a handful of researchers have sought to compare efforts across two or more industries. ${ }^{73,74,76,77}$

In some cases, these campaigns have targeted industry practices that contribute directly to disparities in cancer. For example, in Philadelphia, a coalition of African American, community, church, and health organizations led a campaign to force R.J. Reynolds Tobacco Company to drop plans for test marketing Uptown cigarettes, a brand aimed at African Americans. ${ }^{79}$ Similarly, a coalition of Chicago Black and Latino groups and the attorneys general of several states worked together to force R.J. Reynolds to modify its Kool Mixx, a tobacco promotional campaign that used hip hop music to appeal to young Blacks and Latinos. ${ }^{38}$ Also in Chicago, a neighborhood coalition and a university joined forces to advocate bans on alcohol and tobacco billboards in lowincome communities of color. ${ }^{80}$ Many communities have used land-zoning regulations to reduce the density of alcohol, tobacco, and fast food establishments. ${ }^{81}$ In other cases, community or health advocacy organizations have launched counter-advertising campaigns using African American or Latino images and themes designed to counteract industry's use of similar elements. In schools across the country, including many in big cities with high proportions of low-income students, parents and advocacy organizations are working to force food companies to end marketing of high-calorie low-nutrient foods within schools. ${ }^{82}$ Finally, some low-income neighborhoods have sponsored farmers markets in order to make fresh fruits and vegetables more accessible. ${ }^{83}$

In sum, public health campaigns to modify TAF industry practices that increase cancer risk are a promising strategy for the primary prevention of cancer. By focusing attention on this domain of practice, conducting systematic studies of the efficacy of various intervention strategies, and better documenting the many existing efforts to change industry practices, researchers and health professionals can bring evidence-based lessons to policymakers that would assist them in selecting policies to maximize the potential for primary prevention of cancer and the reduction or elimination of cancer disparities. 


\section{Conclusion}

In this commentary, we have articulated the role that corporate policies and practice may play in shaping disparities in cancer morbidity and mortality, highlighted the societal costs that may be associated with these corporate practices, and summarized some efforts that have been used successfully to influence corporate practices for the purposes of improving population health. We conclude with recommendations for research, policy, and practice based on these observations.

First, epidemiologic research about the consequences of corporate practices remains in its infancy. Although, to some extent, it is self-evident that within a market-driven economy corporate practices will influence consumer behavior and consumer health, there are very few empirical studies that have explicitly considered the relation between corporate practices and health in such a way as to provide quantitative estimates of the role of these practices as health determinants. Public health inquiry about the contribution of factors at multiple levels of influence has grown tremendously in recent years, spurred both by a renewal of interest in the social production of health and disease, and by advances in analytic techniques that allow us to examine the contribution of factors at multiple levels empirically. However, apart from some research about corporate practices related to tobacco, limited empirical inquiry has systematically examined the role of corporate practices in the cancer outcomes discussed here. We suggest that future work seek to quantify the burden of cancer attributable to specified corporate practices (e.g., marketing, pricing), much as McGinnis and Foege ${ }^{48}$ have estimated the burden of mortality attributable to individual behavior.

Second, there are several areas in which health policy can be brought to bear on the issue of corporate policies producing health, illness, and disparities. Health policy practitioners and researchers as well as professional groups such as the American Cancer Society must work toward introducing heath into the political discussion about corporate and product regulation. By joining the government-corporate decision-making axis, health policy researchers and advocates can contribute to encouraging healthy corporate practices and discouraging less healthy ones. Health policy efforts can also be directed toward direct engagement in shaping product design and manufacture. Historically, the role of public health in influencing corporate practices with respect to health has focused more on occupational and environmental than on consumer health. By analyzing successes and limitations in protecting workers' health and the environment against corporate harm, it may be possible to learn lessons relevant to the primary prevention of cancer and cancer disparities.

Third, public health practitioners can support policies that promote healthy consumption patterns and combat less healthy ones. For example, public health efforts in the past have been successful in limiting advertising to children of clearly unhealthy products such as cigarettes or alcohol ${ }^{84,85}$ but so far have failed to regulate food advertising successfully. These efforts have gone further in some countries than they have in the U.S. For example, based on the principle that marketing messages have a duty to provide accurate information, Canadian cigarette packaging has long carried stark warnings about the deleterious consequences of smoking and images of tobacco-related 
diseases. These warnings must cover half of the front and back of the package. In addition to regulating marketing efforts, people in the world of pubic health can be engaged in their own efforts to use market forces to counter potentially harmful influences of corporate practices. The recent successes of the Truth campaign to limit youth tobacco use illustrate the potential for counter-advertising that challenges industry manipulation of vulnerable populations. ${ }^{86}$

Fourth, public health professionals and researchers can join efforts to re-frame primary prevention of cancer as an achievable goal that requires policy change. Previous research on public health communications suggests that health campaigns that raise issues of fairness and justice, that focus on protecting children, and that use existing, trusted channels and networks for mobilization are effective in bringing about policy change. ${ }^{73,74,87}$ By applying these lessons to the primary prevention of cancer, health professionals can contribute to more effective campaigns for the elimination of cancer disparities.

Fifth, health professionals must be persuaded that it is both possible and necessary to move beyond secondary prevention of cancer and a narrow focus on improving access to cancer screening and counseling. By demonstrating that it is feasible and practical to identify and modify the more fundamental determinants of cancer incidence and disparities, it may be possible to engage health professionals in the acceleration of reductions in the overall and disparate burden of cancer on various populations.

In sum, substantial evidence shows that practices of the tobacco, alcohol, and food industries contribute to cancer incidence and to socioeconomic and racial/ethnic disparities in cancer morbidity and mortality. Other evidence suggests that changing such corporate practices can reduce consumption of carcinogenic tobacco, alcohol, and food products. Making the reduction of tobacco, alcohol, and food corporate practices that contribute to cancer a research and policy priority offers significant promise of achieving national cancer goals, given high rates of cancer, wide socioeconomic and racial/ethnic disparities in certain types of cancer, and limited success to date in primary prevention of cancer.

\section{Notes}

1. U.S. Department of Health and Human Services. Healthy People 2010: understanding and improving health. 2nd ed. Washington, DC: U.S. Government Printing Office, 2000 .

2. National Cancer Institute (NCI). Cancer trends progress report-2005 update. Bethesda, MD: National Cancer Institute, NIH, DHHS, 2005 Dec. Available at http:// progressreport.cancer.gov.

3. American Cancer Society (ACS). Cancer prevention and early detection facts \& figures 2006. Atlanta, GA: ACS, 2006.

4. American Society of Clinical Oncology. American Society of Clinical Oncology policy statement update: tobacco control-reducing cancer incidence and saving lives. J Clin Oncol. 2003 Jul 15;21(14):2777-86.

5. Colditz GA, Samplin-Salgado M, Ryan CT, et al. Harvard report on cancer prevention, volume 5: fulfilling the potential for cancer prevention: policy approaches. Cancer Causes Control. 2002 Apr;13(3):199-212. 
6. American Cancer Society. Cancer facts \& figures for African Americans 2005-2006. Atlanta, GA: ACS, 2005.

7. Smedley BD, Haynes MA, eds. Institute of Medicine, Committee on Cancer Research. The unequal burden of cancer: an assessment of NIH research and programs for ethnic minorities and the medically underserved. Washington, DC: National Academy Press, 1999.

8. Broder S. The human costs of cancer and the response of the National Cancer Program. Cancer. 1991;67(6 Suppl):1716-7.

9. Singh GK, Miller BA, Hankey BF. Changing area socioeconomic patterns in U.S. cancer mortality, 1950-1998: Part II-Lung and colorectal cancers. J Natl Cancer Inst. 2002 Jun 19;94(12):916-25.

10. Singh GK, Miller BA, Hankey BF, et al. Area socioeconomic variations in U.S. cancer incidence, mortality, stage, treatment, and survival, 1975-1999. NCI Cancer Surveillance Monograph Series, Number 4. Bethesda, MD: NCI, 2003. (NIH Publication No. 03-5417.)

11. American Cancer Society. Cancer prevention and early detection facts and figures 2005. Atlanta, Ga: ACS, 2005.

12. Flenaugh EL, Henriques-Forsythe MN. Lung cancer disparities in African Americans: health versus health care. Clin Chest Med. 2006 Sep;27(3);431-9.

13. U.S. Department of Health and Human Services (DHHS). Tobacco use among U.S. racial/ethnic minority groups-African Americans, American Indians and Alaska Natives, Asian Americans and Pacific Islanders, and Hispanics: a report of the Surgeon General. Atlanta: GA: U.S. DHHS, Centers for Disease Control and Prevention, National Center for Chronic Disease Prevention and Health Promotion, Office of Smoking and Health, 1998.

14. Paeratakul S, Lovejoy JC, Ryan DH, et al. The relation of gender, race and socioeconomic status to obesity and obesity comorbidities in a sample of U.S. adults. Int J Obes Relat Metab Disord. 2002 Sep;26(9):1205-10.

15. Dawson DA. Beyond black, white and Hispanic: race, ethnic origin and drinking patterns in the United States. J Subst Abuse. 1998;10(4):321-39.

16. Schmidt LA, Ye Y, Greenfield TK, et al. Ethnic disparities in clinical severity and services for alcohol problems: results from the National Alcohol Survey. Alcohol Clin Exp Res. 2007 Jan;31(1):48-56.

17. Byers TE, Mouchawar J, Marks J, et al. The American Cancer Society challenge goals. How far can cancer rates decline in the U.S. by the year 2015? Cancer. 1999 Aug; 86(4):715-27.

18. Link BG, Phelan J. Social conditions as fundamental causes of disease. J Health Soc Behav. 1995;Spec No:80-94.

19. Naff JL, Coté ML, Wenzlaff AS, et al. Racial differences in cancer risk among relatives of patients with early onset lung cancer. Chest. 2007 May;131(5):1289-94.

20. Brownell KD, Horgen KB. Food fight: the inside story of the food industry, America's obesity crisis and what we can do about it. New York: McGraw-Hill, 2004.

21. Freudenberg N. Public health advocacy to change corporate practices: implications for health education practice and research. Health Educ Behav. 2005 Jun;32(3): 298-319.

22. Giesbrecht N. Roles of commercial interests in alcohol policies: recent developments in North America. Addiction. 2000 Dec;95 Suppl 4:S581-95. 
23. Kluger R. Ashes to ashes: America's hundred year cigarette war, the public health, and the unabashed triumph of Philip Morris. New York: Vintage, 1997.

24. Wiist WH. Public health and the anticorporate movement: rationale and recommendations. Am J Public Health. 2006 Aug;96(8):1370-5.

25. Kawachi I, Berkman LF, eds. Neighborhoods and health. New York: Oxford University Press, 2003.

26. Marmot M. The influence of income on health: views of an epidemiologist. Health Aff (Millwood). 2002 Mar-Apr;21(2):31-46.

27. Wilkinson RG. Unhealthy societies: the afflictions of inequality. New York: Routledge, 1996.

28. Bell J, Standish M. Communities and health policy: a pathway for change. Health Aff (Millwood). 2005 Mar-Apr;24(2):339-42.

29. Centers for Disease Control and Prevention, National Center for Chronic Disease Prevention and Health Promotion. Addressing social determinants of disparities in health: learning by doing. Forum, Atlanta (GA), October 28-29, 2003. Available at http://www.cdc.gov/sdoh/.

30. Link BG, Phelan JC. Fundamental sources of health inequalities. In: Mechanic D, Rogut LB, Colby DC, et al., eds. Policy challenges in modern health care. New Brunswick, NJ: Rutgers University Press, 2005; 71-84.

31. Krieger N. Defining and investigating social disparities in cancer: critical issues. Cancer Causes Control. 2005 Feb;16(1):5-14.

32. Weissman JS, Schneider EC. Social disparities in cancer: lessons from a multidisciplinary workshop. Cancer Causes Control. 2005 Feb;16(1):71-4.

33. Link BG, Northridge ME, Phelan JC, et al. Social epidemiology and the fundamental cause concept: on the structuring of effective cancer screens by socioeconomic status. Milbank Q. 1998;76(3):375-402, 304-5.

34. Landrine $\mathrm{H}$, Klonoff EA, Campbell $\mathrm{R}$, et al. Sociocultural variables in youth access to tobacco: replication 5 years later. Prev Med. 2000 May;30(5):433-7.

35. Moore DJ, Williams JD, Qualls WJ. Target marketing of tobacco and alcohol-related products to ethnic minority groups in the United States. Ethn Dis. 1996 Winter-Spring; 6(1-2):83-98.

36. Williams DR, Jackson PB. Social sources of racial disparities in health. Health Aff (Millwood). 2005 Mar-Apr;24(2):325-34.

37. Centers for Disease Control and Prevention (CDC). Annual smoking-attributable mortality, years of potential life lost, and economic costs-United States, 1995-1999. MMWR. 2002 Apr 12;51(14):300-3.

38. National African American Tobacco Prevention Network (NAATPN). National African American Tobacco Network demands that Kool's stop targeting the hip-hop generation. Press Release. Summerville, NC: NAATPN, 2004 Apr 8.

39. Slade J. Marketing policies. In: Rabin RL, Sugarman SD, eds. Regulating tobacco. New York: Oxford University Press, 2001; 72-110.

40. Rosenberg NJ, Siegel M. Use of corporate sponsorship as a tobacco marketing tool: a review of tobacco industry sponsorship in the USA, 1995-99. Tob Control. 2001 Sep;10(3):239-46.

41. Givel MS, Glantz SA. Tobacco lobby political influence on US state legislatures in the 1990s. Tob Control. 2001 Jun;10(2):124-34.

42. Menashe CL, Siegel M. The power of a frame: an analysis of newspaper coverage 
of tobacco issues-United States, 1985-1996. J Health Commun. 1998 Oct-Dec; 3(4):307-25.

43. Wilson JF. Liver cancer on the rise. Ann Intern Med. 2005 Jun 21;142(12 Pt 1): 1029-32.

44. Schottenfeld D, Beebe-Dimmer JL. Advances in cancer epidemiology: understanding causal mechanisms and the evidence for implementing interventions. Annu Rev Public Health. 2005;26:37-60.

45. Blot WJ, McLaughlin JK, Winn DM, et al. Smoking and drinking in relation to oral and pharyngeal cancer. Cancer Res. 1988 Jun 1;48(11):3282-7.

46. Foster SE, Vaughan RD, Foster WH, et al. Estimate of the commercial value of underage drinking and adult abusive and dependent drinking to the alcohol industry. Arch Pediatr Adolesc Med. 2006 May;160(5):473-8.

47. Alaniz ML. Alcohol availability and targeted advertising in racial/ethnic minority communities. Alcohol Health Res World. 1998;22(4):286-9.

48. McGinnis JM, Foege WH. Actual causes of death in the United States. JAMA. 1993; 270:2207-12.

49. Doll R, Peto R. The causes of cancer: quantitative estimates of avoidable risks of cancer in the United States today. J Natl Cancer Inst. 1981 Jun;66(6):1191-308.

50. Key TJ, Schatzkin A, Willett WC, et al. Diet, nutrition and the prevention of cancer. Public Health Nutr. 2004 Feb;7(1A):187-200.

51. McMillan DC, Sattar N, McArdle CS. ABC of obesity. Obesity and cancer. BMJ. 2006 Nov 25;333(7578):1109-11.

52. Vigneri P, Frasca F, Sciacca L, et al. Obesity and cancer. Nutr Metab Cardiovasc Dis. 2006 Jan;16(1):1-7.

53. Mai V, Kant AK, Flood A, et al. A. Diet quality and subsequent cancer incidence and mortality in a prospective cohort of women. Int J Epidemiol. 2005 Feb;34(1):54-60.

54. Vaino H, Bianchini F, eds. IARC Handbooks of Cancer Prevention. Vol. 8, Fruits and Vegetables. Oxford, UK: Lyon International Agency for Research on Cancer, 2003.

55. Calle EE, Rodriguez C, Walker-Thurmond K, et al. Overweight, obesity, and mortality from cancer in a prospectively studied cohort of U.S. adults. N Engl J Med. 2003 Apr 24;348(17):1625-38.

56. Putnam J, Allshouse J, Kantor LS. U.S. per capita food supply trends: more calories, refined carbohydrates, and fats. Food Review. 2002;25(3):2-15. Available at http://www .ers.usda.gov/publications/FoodReview/DEC2002/frvol25i3a.pdf.

57. Nestle, M. Food politics: how the food industry influences nutrition and health. Berkeley, CA: University of California Press, 2002.

58. Carson NJ, Rodriguez D, Audrain-McGovern J. Investigation of mechanisms linking media exposure to smoking in high school students. Prev Med. 2005 Aug; 41(2):511-20.

59. Choi WS, Ahluwalia JS, Harris KJ, et al. Progression to established smoking: the influence of tobacco marketing. Am J Prev Med. 2002 May;22(4):228-33.

60. Reidpath DD, Burns C, Garrard J, et al. An ecological study of the relationship between social and environmental determinants of obesity. Health Place. 2002 Jun; $8(2): 141-5$.

61. Schneider JE, Reid RJ, Peterson NA, et al. Tobacco outlet density and demographics at the tract level of analysis in Iowa: implications for environmentally based prevention initiatives. Prev Sci. 2005 Dec;6(4);319-25.

62. Harwood EM, Erickson DJ, Fabian LE, et al. Effects of communities, neighbor- 
hoods and stores on retail pricing and promotion of beer. J Stud Alcohol. 2003 Sep; 64(5):720-6.

63. Kuo M, Wechsler H, Greenberg P, et al. The marketing of alcohol to college students: the role of low prices and special promotions. Am J Prev Med. 2003 Oct;25(3):204-11.

64. Monardi F, Glantz SA. Are tobacco industry campaign contributions influencing state legislative behavior? Am J Public Health. 1998 Jun;88(6):918-23.

65. Luke DA, Krauss M. Where there's smoke there's money: tobacco industry campaign contributions and U.S. Congressional voting. Am J Prev Med. 2004 Dec;27(5): 363-72.

66. Kersh R, Morone J. The politics of obesity: seven steps to government action. Health Aff (Millwood). 2002 Nov-Dec;21(6):142-53.

67. Mello MM, Rimm EB, Studdert DM. The McLawsuit: the fast-food industry and legal accountability for obesity. Health Aff (Millwood). 2003 Nov-Dec;22(6):207-16.

68. Balbach ED, Gasior RJ, Barbeau EM. R.J. Reynolds' targeting of African Americans: 1988-2000. Am J Public Health. 2003 May;93(5):822-7.

69. Zenk SN, Schulz AJ, Israel BA, et al. Neighborhood racial composition, neighborhood poverty, and the spatial accessibility of supermarkets in metropolitan Detroit. Am J Public Health. 2005 Apr;95(4):660-7.

70. LaVeist TA. Disentangling race and socioeconomic status: a key to understanding health inequalities. J Urban Health. 2005 Jun;82(2 Suppl 3):iii26-34.

71. Schmidt M, Affenito SG, Striegel-Moore R, et al. Fast-food intake and diet quality in black and white girls: the National Heart, Lung, and Blood Institute Growth and Health Study. Arch Pediatr Adolesc Med. 2005 Jul;159(7):626-31.

72. Sturm R, Datar A. Body mass index in elementary school children, metropolitan area food prices and food outlet density. Public Health. 2005 Dec;119(12):1059-68.

73. Dorfman L, Wallack L, Woodruff K. More than a message: framing public health advocacy to change corporate practices. Health Educ Behav. 2005 Jun;32(3):320-36.

74. Freudenberg N, Bradley SP, Serrano M. Public health campaigns to change industry practices that damage health: an analysis of 12 case studies. Health Educ Behav. 2007 Dec 12 [Epub ahead of print].

75. Pertschuk M. Smoke in their eyes: lessons in movement leadership from the tobacco wars. Nashville, TN: Vanderbilt University Press, 2001.

76. Jacobson PD, Soliman S. Litigation as pubic health policy: theory or reality? J Law Med Ethics. 2002 Summer;30(2):224-38.

77. Nathanson CA. Social movements as catalysts for policy change: the case of smoking and guns. J Health Polit Policy Law. 1999 Jun;24(3):421-88.

78. Yach D, McKee M, Lopez AD, et al. Improving diet and physical activity: 12 lessons from controlling tobacco smoking. BMJ. 2005 Apr 16;330(7496):898-900.

79. Robinson RG, Sutton C. The coalition against uptown cigarettes. In: Jernigan D, Wright PA, eds. Making news, changing policy: case studies of media advocacy on alcohol and tobacco issues Washington, DC: U.S. Department of Health and Human Services, 1994; 89-108.

80. Hackbarth DP, Schnopp-Wyatt D, Katz D, et al. Collaborative research and action to control the geographic placement of outdoor advertising of alcohol and tobacco products in Chicago. Public Health Rep. 2001 Nov-Dec;116(6):558-67.

81. Ashe M, Jernigan D, Kline R, et al. Land use planning and the control of alcohol, tobacco, firearms, and fast food restaurants. Am J Public Health. 2003 Sep;93(9): 1404-8. 
82. Peterson KE, Fox MK. Addressing the epidemic of childhood obesity through schoolbased interventions: what has been done and where do we go from here? J Law Med Ethics. 2007 Spring;35(1):113-30.

83. Bacalor J, Wilson N, Glowa M. The fight against food redlining. Critical Moment. 2007;21. Available at http://criticalmoment.org/node/623.

84. Rigotti N. Reducing the supply of tobacco to youth. In: Rabin RL, Sugarman SD, eds. Regulating tobacco. New York: Oxford University Press, 2001; 143-75.

85. Wagenaar AC, Lenk KM, Toomey TL. Policies to reduce underage drinking: a review of the recent literature. Recent Dev Alcohol. 2005;17:275-97.

86. Farrelly MC, Davis KC, Haviland ML, et al. Evidence of a dose-response relationship between "truth" antismoking ads and youth smoking prevalence. Am J Public Health. 2005 Mar;95(3):425-31.

87. Wallack L, Lawrence R. Talking about public health: developing America's "second language." Am J Public Health. 2005 Apr;95(4):567-70. 